\title{
Optimal condition-based maintenance strategy under periodic inspections for traction motor insulations
}

\author{
Jian ZHANG ${ }^{1}$, Ji-en MA ${ }^{\dagger 2}$, Xiao-yan $\mathrm{HUANG}^{1}$, You-tong $\mathrm{FANG}^{1}$, He ZHANG ${ }^{3}$ \\ $\left({ }^{1}\right.$ College of Electrical Engineering, Zhejiang University, Hangzhou 310027, China) \\ $\left({ }^{2}\right.$ China Academy of West Region Development, Zhejiang University, Hangzhou 310027, China) \\ $\left({ }^{3}\right.$ Department of Electrical and Electronic Engineering, The University of Nottingham, Nottingham NG7 2RD, UK) \\ †E-mail: jienma@126.com
}

Received Oct. 15, 2014; Revision accepted July 7, 2015; Crosschecked July 9, 2015

\begin{abstract}
Insulation failure is a crucial failure mode of traction motors. Insulation deteriorates under both fatigue load and shock. This paper focuses on proposing an optimal insulation condition-based maintenance strategy. By combining the information obtained from periodic inspections with historic life information, an integrated model of time-based maintenance and condition-based model is proposed, in which random shocks following Poisson process are also taken into account. In this model we define that insulation has three states: normal state, latent failure state, and functional failure state. Normal state and latent failure state differ in their operating cost, proneness to functional failure, and survival probability under extreme shocks. Preventive maintenance (PM) will be launched if an inspection result exceeds the threshold or if the operating time reaches the critical age. One operating cycle ends as soon as a preventive maintenance or a corrective maintenance is completed. Moreover, an optimization model is established, which takes minimal cost per unit time as the objective, and inspection interval and critical age as the optimization variables. Finally, a numerical example illustrates the analytic results.
\end{abstract}

Key words: Traction motor insulation, Condition-based maintenance (CBM), Preventive maintenance (PM), Shock doi: $10.1631 /$ jzus.A1400311

Document code: A

CLC number: TH17

\section{Introduction}

Traction motors are key parts of high speed trains (Fang, 2011), and insulation failure is a key failure mode. There are about $37 \%$ of traction motor failures resulting from insulation failures (Zhou et al., 2006). The reliability of insulation has a direct effect on the safety and performance of high speed trains.

\footnotetext{
‡ Corresponding author

* Project supported by the National Natural Science Foundation of China (Nos. 51407158, 51177144, and U1434202), and the National High-Tech R\&D Program (863 Program) of China (No. 2011AA11 A101-01)

(D) ORCID: Jian ZHANG, http://orcid.org/0000-0002-8411-8131; Ji-en MA, http://orcid.org/0000-0001-6970-3634

C Zhejiang University and Springer-Verlag Berlin Heidelberg 2015
}

At the rated rotating speed, the winding insulation of traction motors is subject to a continuous high-voltage square wave pulse instead of a sinusoidal voltage. Compared with a sinusoidal voltage, a high-voltage square wave may apply a higher voltage with a high frequency. The high frequency also intensifies the aging effect of dielectric loss, partial discharge, and space charges on the insulation, which may provoke premature failure.

Fatigue and shock play a primary role in traction motor insulation failure. Fatigue is associated with electrical, thermal, and mechanical aging, and shocks arise from the interventions of extremelyhigh-voltage pulses of regional over-voltage, over switched voltage, ring effect, and so on. Therefore, a traction motor insulation can be treated as a deteriorating system subject to the combination of fatigue load and shock load. 
Timely maintenance can free traction motor insulations from sudden catastrophic breakdown. Maintenance planning is of vital importance to guarantee safety and availability. Time-based maintenance (TBM) and condition-based maintenance (CBM) are two mainstream strategies of preventive maintenance (PM) (Liu et al., 2007; Asadzadeh and Azadeh, 2014; Gao et al., 2014). Up to now, TBM based on historical life information is the main method for insulation maintenance, where maintenance is scheduled based on a pre-specified age threshold. It has obvious drawbacks, such as either excessive or insufficient maintenance (Ma, 2008). With the development of sophisticated inspection technology on key performance parameters, such as the quantity of partial discharge, the polarization index, and winding insulation resistance, $\mathrm{CBM}$ shows great potential to substitute for TBM. However, as far as we are aware no CBM policy specific for motor insulations has been proposed in previous studies.

The issue of CBM policies for deteriorating systems has attracted a lot of attention. Most CBM models rely on the accessibility to degradation process information (Lu and Liu, 2014; Shi and Zeng, 2014). Gebraeel et al. (2005) presented a maintenance model combining the estimation of residual life distribution based on the Bayes theory and PM, in which the degrading function was assumed to be linear. Yang and Klutke (2000) and van Noortwijk (2009) described the degrading characteristics of deteriorating systems by a Gamma process and a Levy process.

Life data collected by the manufactures of insulation materials and the accelerating test results before delivery both make the life distribution accessible, and the integration of CBM and TBM is both possible and a significant development in engineering practice. Up to now research on TBM and CBM has remained separate. Data sharing between these two maintenance modes is a problem and worthy of in-depth research (Ahmad and Kamaruddin, 2012). By sharing the statistical process data, some researchers attempted to establish the joint optimal models of CBM and TBM for manufacturing systems (Panagiotidou and Tagaras, 2008; 2010; 2012; Yin et al., 2015). This model is innovative by maximally using the life information and state information and can be extended to deteriorating system maintenance with modification. In addition, Tang et al. (2015) provided an autoregressive model to describe system degradation.
For shock models, Tang and Lam (2006) and Lam (2009) proposed a maintenance model for deteriorating systems under $\delta$-shock, which worked out the maintenance plan on the basis of the interval between two shocks. Hu (1995) and Montoro-Cazorla and Pérez-Ocón (2014) established the model considering the shock effect by adopting a Markovian process. All the above-mentioned shock models assumed that each shock may lead to a discount of residual life. The accumulation of life loss is used as a reference to set up maintenance models, but these do not match the extreme shock situation of traction motor insulations. Some researchers also extended the degradation-threshold-shock model of optimal maintenance, which integrated degradation and shock effects and described them with stochastic process models (Wang et al., 2011; Castro, 2013; Lin et al., 2014; 2015; Caballé et al., 2015; Castro et al., 2015).

In summary, for the application of CBM in insulation maintenance, it is a big challenge to establish an integrated model of TBM and CBM, one which explicitly takes extremely-high-voltage shock effect into account. In this paper, we propose a maintenance policy in which periodic inspections are conducted to evaluate insulation performance and the preventive maintenance actions are initialized by exceeding the critical age or exceeding a prespecified inspection threshold. An optimization model is set up, which takes inspection interval and the critical age as the optimization variables, and minimal maintenance cost per time unit as the optimization objective.

In this paper, we first describe the problem setting, and the basic assumption of the maintenance strategy with details. Then, we focus on the optimization model and establish the optimization model ignoring the shock effect as a preparation for future analysis. At last, the proposed model is validated through a numerical example.

\section{Problem statement and description}

The proposed maintenance strategy is described as follows.

1. The failure modes of traction motor insulations can be divided into two categories (Yao et al., 2013): 
Failure $a$ : The first type of failure, the situation that functional failure occurs while inspection data does not reach or exceed the threshold value. A corrective maintenance $(\mathrm{CM})$ should be executed.

Failure $b$ : The second type of failure, the situation that inspection data reaches or exceeds the threshold value with no occurrence of functional failure. A PM should be executed.

Failure $a$ is directly observable and selfannouncing, while Failure $b$ can only be detected through offline inspections. Fig. 1 describes the operating and failure modes of traction motor insulations.

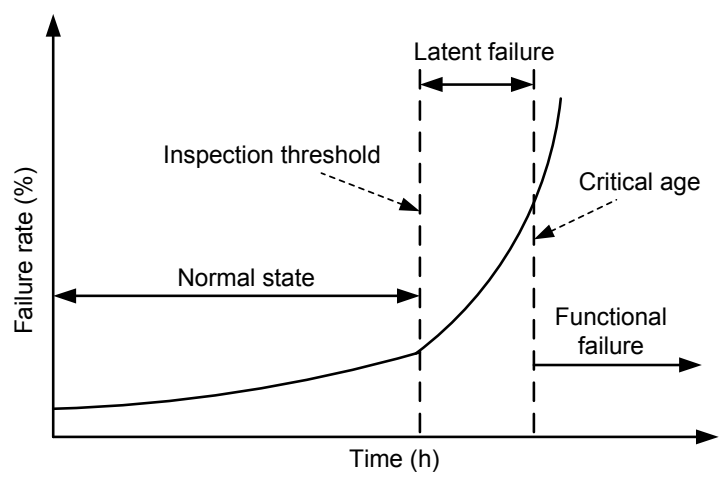

Fig. 1 Operating and failure modes of insulations

2. Traction motor insulations can work in two states, normal state and latent failure state. Latent failure state is a transition state between normal state and functional failure state. During this period, insulations have shifted from a stable period to an accelerating aging period, and their failure rate increases acutely, that is to say the probability that functional failure occurs in this state is higher than that in normal state. $s=\{0,1,2\}$ is the state set of traction motor insulations, and states 0,1 , and 2 represent normal state, latent failure state, and functional failure state, respectively. When insulation is under state 1 , the operation cost of traction motors will increase due to the decrease of motor efficiency. Under either state 0 or state 1 , insulation can jump to state 2 . Note that the probability of the jump from state 1 to state 2 is higher than that from state 0 to state 2. Fig. 2 clarifies the state transition mechanism, in which $P_{\mathrm{S} i}$ is the failure probability at state $i(i=0,1)$ after each shock, $f(t)$ is the probability density function (PDF) of the time from normal state to latent failure state, $\varphi_{0}(t)$ is the PDF of the time to functional failure state in normal state, and $\varphi_{1}(t)$ is the PDF of the time to functional failure state in latent failure state. The difference between Fig. 2 and the one proposed by Panagiotidou and Tagaras (2010) is that shocks are integrated into the state transition process.

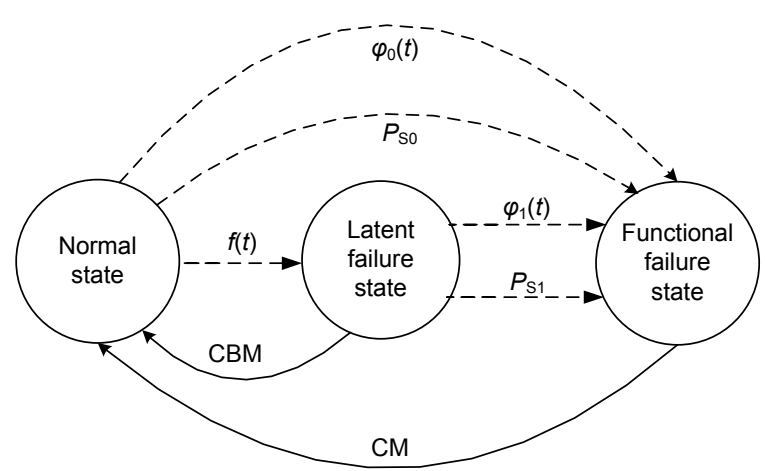

Fig. 2 State transition mechanism

3. The offline inspections on the performance indicator are performed periodically (assuming inspection is perfect). Generally, the inspection times should be an arbitrary value independent of each other. However, the optimization model itself is already extremely complicated, and if we set the inspection times as arbitrary values, which may add more complexity to the optimization model, it is too hard to obtain a convergent solution in practice. So for practical feasibility, the inspection will be taken with a constant interval or the interval should obey a simple rule. In this study, a constant inspection interval is adopted to simplify the optimization model. When the performance of insulations is lower than the national standards, Failure $b$ happens, and PM is called for to restore insulations to the normal state. For simplicity, we define the duration of $N$ inspection intervals as the critical age, beyond which the failure rate of insulations will be unacceptably high. If insulations can survive $N$ inspection intervals without any state transition or failure, a PM is scheduled to be carried out. Once Failure $a$ happens, the motor has to stop without any delay and an emergency control mechanism should be launched to let other traction motors share its traction load. In this situation, CM is indispensable. Once a maintenance action is triggered, either PM or CM, an operation cycle ends and a replacement action is 
performed due to the high safety requirement of high speed trains without considering the delivery time of spare parts. Insulations will restore to an "as-goodas-new" state after maintenance, which also indicates the start of a new operation cycle.

4. Insulation is subject to external random extremely-high-voltage shock which occurs according to a Poisson process with $\lambda$ as the intensity parameter. The failure probability after each shock for state 0 is smaller than that for state $1\left(P_{\mathrm{S} 0}<P_{\mathrm{S} 1}\right)$. Here we ignore the influence of extreme shocks on insulation residual life (Chen and $\mathrm{Li}, 2008$ ).

5. $A\left(t_{i}\right)=\left\{a_{0}, a_{1}, a_{2}\right\}$ is the maintenance action set at time $t_{i}$, where $a_{0}$ represents no maintenance action, and $a_{1}$ and $a_{2}$ are PM and CM, respectively.

6. $E=\left\{E\left(T_{0}\right), E\left(T_{1}\right), P_{\mathrm{PM}}, P_{\mathrm{CM}}, T_{\mathrm{C}}, T_{\mathrm{IN}}\right\}$ is the operation state parameter set. $E\left(T_{i}\right)$ is the expected time at state $i(i=0,1)$ in an operation cycle; $P_{\mathrm{PM}}$ and $P_{\mathrm{CM}}$ are the probabilities to carry out PM and CM within one cycle, respectively; $T_{\mathrm{C}}$ is the pre-defined critical age, and $T_{\mathrm{IN}}$ is the interval between two continuous inspections. Note that $T_{\mathrm{IN}}$ is a fixed value and $T_{\mathrm{C}}=N T_{\mathrm{IN}}$.

7. $C=\left\{C_{0}, C_{1}, C_{\mathrm{PM}}, C_{\mathrm{CM}}, C_{\mathrm{IN}}, \mathrm{CPT}\right\}$ is the cost set. $C_{i}$ is the operation cost at state $i(i=0,1)$ and $C_{1}>C_{0} ; C_{\mathrm{PM}}, C_{\mathrm{CM}}$, and $C_{\mathrm{IN}}$ are the costs of one PM, one $\mathrm{CM}$, and one inspection, respectively; and CPT is the operation cost per unit time within one cycle.

\section{Mathematical model development}

In this section, we will establish an optimization model for traction motor insulation maintenance, in which the minimal CPT in an operation cycle is regarded as the optimization objective. Since CPT is a function of the variables of $N$ and $T_{\mathrm{IN}}$, they are defined to be the decision variables with the constraints set as follows: $\left\{T_{\mathrm{C}}>T_{\mathrm{IN}}>0 ; C_{1}>C_{0}>0 ; C_{\mathrm{CM}}>C_{\mathrm{PM}}>0\right.$; $\left.P_{\mathrm{S} 1}>P_{\mathrm{S} 0} ; N \geq 2\right\}$.

The expected operation time within one operation cycle comprises the expected operation time at state 0 and the expected operation time at state 1 . The expected cost within one cycle includes the expected costs of operation at state 0 , operation at state 1, inspections, PM, and CM.

Then, the objective function can be expressed as

$$
\mathrm{CPT}=\frac{E(C)}{E(T)},
$$

where $E(C)$ and $E(T)$ are the expected cost and expected operation time of one cycle, respectively, and

$$
\begin{aligned}
E(C)= & E\left(T_{0}\right) C_{0}+E\left(T_{1}\right) C_{1}+P_{\mathrm{PM}} C_{\mathrm{PM}} \\
& +P_{\mathrm{CM}} C_{\mathrm{CM}}+E(\mathrm{IN}) C_{\mathrm{IN}}, \\
E(T)= & E\left(T_{0}\right)+E\left(T_{1}\right),
\end{aligned}
$$

where $E(\mathrm{IN})$ is the expected number of inspections within one cycle.

In the rest of this section, we focus on the derivation of the variables in this model.

\subsection{Failure rate of insulations under shocks}

Suppose $\Psi(t, i)$ is the survival cumulative distribution function (CDF) of insulations under highvoltage shocks in the duration of $t$ when operating in state $i$. According to Poisson process theory, we can obtain

$$
\Psi(t, i)=\sum_{k=0}^{+\infty}\left[\frac{(\lambda t)^{k}}{k !} \mathrm{e}^{-\lambda t}\left(1-P_{\mathrm{S} i}\right)^{k}\right]=\exp \left(-\lambda t P_{\mathrm{S} i}\right)
$$

The failure CDF under shocks within period $t$ at state $i(i=0,1)$ is

$$
\bar{\Psi}(t, i)=1-\Psi(t, i)
$$

and the corresponding PDF is

$$
\phi(t, i)=\lambda P_{\mathrm{S} i} \exp \left(-\lambda t P_{\mathrm{S} i}\right)
$$

\subsection{State transition probability during a single inspection interval}

Suppose $t_{i-1}(i \geq 1)$ is the time when the $(i-1)$ th inspection is taken, in which $t_{0}$ means the initial time of a new operation cycle and at $t_{0}$ insulations are asgood-as-new. Suppose $s\left(t_{i}\right)$ is the state at time $t_{i}$, and if $s\left(t_{i-1}\right)=0$, traction motor insulation will continue to work. In the duration of $t_{i-1}-t_{i}$, four scenarios may occur: 
(1) Scenario $a$ : during the interval of $t_{i-1}-t_{i}$, no state transition occurs, that is to say $s\left(t_{i}\right)=0$. Then we can obtain the condition probability of occurrence of Scenario $a$ as

$$
\begin{aligned}
P_{a}^{t_{i}}= & P\left\{s\left(t_{i}\right)=0 \mid s\left(t_{i-1}\right)=0\right. \\
& \left.\bigcup\left(\forall t \in\left(t_{i-1}, t_{i}\right], s(t) \neq 1 \bigcup s(t) \neq 2\right)\right\} \\
= & \frac{1-\Phi_{0}\left(t_{i}\right)}{1-\Phi_{0}\left(t_{i-1}\right)} \frac{1-F\left(t_{i}\right)}{1-F\left(t_{i-1}\right)} \frac{\Psi\left(t_{i}, 0\right)}{\Psi\left(t_{i-1}, 0\right)} \\
= & \frac{\bar{\Phi}_{0}\left(t_{i}\right)}{\bar{\Phi}_{0}\left(t_{i-1}\right)} \frac{\bar{F}\left(t_{i}\right)}{\bar{F}\left(t_{i-1}\right)} \Psi\left(T_{\mathrm{IN}}, 0\right),
\end{aligned}
$$

where $F(t)$ is the CDF of the time from normal state to latent failure state, $\Phi_{0}(t)$ is $\mathrm{CDF}$ of the time to functional failure state in normal state and $\Phi_{1}(t)$ is the $\mathrm{CDF}$ of the time to functional failure state in latent failure state, and

$$
\begin{aligned}
& \bar{\Phi}_{0}(t)=1-\Phi_{0}(t), \\
& \bar{F}\left(t_{i}\right)=1-F\left(t_{i}\right) .
\end{aligned}
$$

(2) Scenario $b$ : during the interval of $t_{i-1}-t_{i}$, the operation state starts at state 0 but ends at state 1 , which means that one state transition from state 0 to state 1 occurs without the occurrence of functional failures. The condition probability of occurrence of Scenario $b$ can be expressed by

$$
\begin{aligned}
P_{b}^{t_{i}}= & P\left\{s\left(t_{i}\right)=1 \mid s\left(t_{i-1}\right)=0 \bigcup\left(\forall t \in\left(t_{i-1}, t_{i}\right], s(t) \neq 2\right)\right\} \\
= & \int_{t_{i-1}}^{t_{i}} \frac{f(t)}{\bar{F}\left(t_{i-1}\right)} \frac{\bar{\Phi}_{0}(t)}{\bar{\Phi}_{0}\left(t_{i-1}\right)} \frac{\bar{\Phi}_{1}\left(t_{i}\right)}{\bar{\Phi}_{1}(t)} \\
& . \Psi\left(t-t_{i-1}, 0\right) \Psi\left(T_{\mathrm{IN}}-t+t_{i-1}, 1\right) \mathrm{d} t
\end{aligned}
$$

where

$$
\bar{\Phi}_{1}(t)=1-\Phi_{1}(t)
$$

(3) Scenario $c$ : at some time between the interval of $t_{i-1}-t_{i}$, one functional failure happens without state transition from state 0 to state 1 . The operation cycle is interrupted. Due to the fact that the probability that functional failure resulting from both the internal factors and shocks simultaneously is quite slim, it is ignored to simplify calculation. The condition probability of occurrence of Scenario $c$ is given by

$$
\begin{aligned}
P_{c}^{t_{i}}= & P\left(s\left(t_{i}\right)=2 \mid s\left(t_{i-1}\right)=0 \bigcup\left(\forall t \in\left(t_{i-1}, t_{i}\right], s(t) \neq 1\right)\right. \\
= & \int_{t_{i-1}}^{t_{i}} \frac{\bar{F}(t)}{\bar{F}\left(t_{i-1}\right)}\left[\frac{\varphi_{0}(t)}{\bar{\Phi}_{0}\left(t_{i-1}\right)} \Psi\left(t-t_{i-1}, 0\right)\right. \\
& \left.+\frac{\bar{\Phi}_{0}(t)}{\bar{\Phi}_{0}\left(t_{i-1}\right)} \phi\left(t-t_{i-1}, 0\right)\right] \mathrm{d} t .
\end{aligned}
$$

(4) Scenario $d$ : at some time between the interval of $t_{i-1}-t_{i}$, one state transition from state 0 to state 1 happens and then one state transition from state 1 to state 2 takes place in order, when the operation cycle is interrupted. The condition probability of occurrence of Scenario $d$ is given by

$$
\begin{aligned}
P_{d}^{t_{i}}= & P\left\{s\left(t_{i}\right)=2 \mid s\left(t_{i-1}\right)=0\right. \\
& \cup\left(\forall t \in\left(t_{i-1}, t^{\prime}\right], s(t)=1\right) \\
& \cup\left(\forall t \in\left(t^{\prime}, t_{i}\right], s(t)=2\right\} \\
= & \int_{t_{i-1}}^{t_{i}} \Delta_{1} \int_{t}^{t_{i}} \Delta_{2} \mathrm{~d} t^{\prime} \mathrm{d} t,
\end{aligned}
$$

where

$$
\begin{gathered}
\Delta_{1}=\frac{f(t)}{\bar{F}\left(t_{i-1}\right)} \frac{\bar{\Phi}_{0}(t)}{\bar{\Phi}_{0}\left(t_{i-1}\right)} \Psi\left(t-t_{i-1}, 0\right), \\
\Delta_{2}=\left[\frac{\varphi_{1}\left(t^{\prime}\right)}{\bar{\Phi}_{1}(t)} \Psi\left(t^{\prime}-t, 1\right)+\frac{\bar{\Phi}_{1}\left(t^{\prime}\right)}{\bar{\Phi}_{1}(t)} \phi\left(t^{\prime}-t_{i-1}, 1\right)\right] .
\end{gathered}
$$

\subsection{Mathematical models for the variables in the optimization model}

\subsubsection{Expected time at state 0 within a cycle}

The expected time at state 0 for traction motor insulations in a cycle includes the following three parts:

(1) No state transition happens in a cycle, and the expected time at state 0 is represented by $T_{0}^{0}$;

(2) One state transition from state 0 to state 1 happens while no state transition from state 0 to state 2 happens, and the expected time at state 0 is represented by $T_{0}^{1}$;

(3) One state transition from state 0 to state 2 happens while no state transition from state 0 to state 1 happens, and the expected time at state 0 is represented by $T_{0}^{2}$. 
Then the expected time at state 0 yields the following expression:

$$
E\left(T_{0}\right)=T_{0}^{0}+T_{0}^{1}+T_{0}^{2}
$$

where

$$
\begin{aligned}
& T_{0}^{0}=T_{\mathrm{C}} \bar{F}\left(T_{\mathrm{C}}\right) \bar{\Phi}_{0}\left(T_{\mathrm{C}}\right) \Psi\left(T_{\mathrm{C}}, 0\right), \\
& T_{0}^{1}=\int_{0}^{T_{\mathrm{C}}} t f(t) \bar{\Phi}_{0}(t) \Psi(t, 0) \mathrm{d} t, \\
& T_{0}^{2}=\int_{0}^{T_{\mathrm{C}}} t \bar{F}(t)\left[\varphi_{0}(t) \Psi(t, 0)+\bar{\Phi}_{0}(t) \phi(t, 0)\right] \mathrm{d} t,
\end{aligned}
$$

and after simplification, we can obtain

$$
E\left(T_{0}\right)=\int_{0}^{T_{C}} \bar{\Phi}_{0}(t) \bar{F}(t) \Psi(t, 0) \mathrm{d} t
$$

\subsubsection{Expected time at state 1 in a cycle}

If the inspection at time $t_{i-1}$ is completed with a result that insulation is at state 0 , we obtain the expression of the probability of its occurrence

$$
\begin{aligned}
P\left(S_{0}^{t_{i-1}}\right) & =P_{a}^{t_{i-1}} \bar{F}\left(t_{i-2}\right) \bar{\Phi}_{0}\left(t_{i-2}\right) \Psi\left(t_{i-2}, 0\right) \\
& =\bar{F}\left(t_{i-1}\right) \bar{\Phi}_{0}\left(t_{i-1}\right) \Psi\left(t_{i-1}, 0\right) .
\end{aligned}
$$

If and only if Scenario $b$ or Scenario $d$ happens during $t_{i-1}-t_{i}$, there exists time that insulation is at state 1 . The expression of the expected time at state 1 during $t_{i-1}-t_{i}$ is given by

$$
E\left(T_{1 i}\right)=P\left(S_{0}^{t_{i-1}}\right) \int_{t_{i-1}}^{t_{i}}\left[P_{b}^{t_{i}}\left(t_{i}-t\right)+\Delta_{1} \int_{t}^{t_{i}} \Delta_{2}\left(t^{\prime}-t\right) \mathrm{d} t^{\prime}\right] \mathrm{d} t .
$$

For the whole cycle, the expression of the expected time at state 1 is given by

$$
E\left(T_{1}\right)=\sum_{i=1}^{N} E\left(T_{1 i}\right)
$$

\subsubsection{Probability of PM and CM in a cycle}

PM is called for in the following two situations:

Situation $a$ : insulation is detected to be at state 1 through the periodic inspection.

Situation $b$ : after $N$ inspection intervals, no state transition happens but insulation is unacceptable. Then a PM is processed.
Through the above analysis, it can be seen that the probability that Situation $a$ happens is equal to the summation of Scenario $b$ happens in each inspection interval, and then it can be derived as

$$
P_{\mathrm{PM}}^{a}=\sum_{i=1}^{N} P_{b}^{t_{i}}
$$

Then we can obtain the probability that PM is called for in a cycle as follows:

$$
P_{\mathrm{PM}}=\sum_{i=1}^{N} P_{b}^{t_{i}}+P\left(S_{0}^{t_{N}}\right)
$$

where $P\left(S_{0}^{t_{i}}\right)$ is the probability of being at state 0 at time $t_{i}$.

Because a cycle will end when either a PM or a $\mathrm{CM}$ is launched, it is clear that

$$
P_{\mathrm{CM}}=1-P_{\mathrm{PM}} \text {. }
$$

\subsubsection{Expected number of inspections in a cycle}

When the inspection at time $t_{i-1}$ is completed, if and only if Scenario $a$ or Scenario $b$ happens, the inspection at time $t_{i}$ is called for, whose probability can be represented by

$$
P_{t_{i}}^{\mathrm{IN}}=P\left(S_{0}^{t_{i-1}}\right)\left(P_{a}^{t_{i}}+P_{b}^{t_{i}}\right) .
$$

So the expected number of inspections within one cycle is

$$
E(\mathrm{IN})=\sum_{i=1}^{m} P\left(S_{0}^{t_{i-1}}\right)\left(P_{a}^{t_{i}}+P_{b}^{t_{i}}\right), \quad m \geq 2 .
$$

\section{Special case}

The above section describes the optimal maintenance model combining TBM with CBM, in which the shock effect is taken into account. In this part, we will establish the model of merely integrating TBM and CBM without the shock effect as a special case for future comparison of their efficiency and analyzing the effect of the shock parameter 
variations on optimization solutions. In the following section, we will put a ${ }^{\wedge}$ above the variables to differentiate from the ones used in previous sections. For example, $\hat{P}_{\mathrm{PM}}$ stands for the probability to carry out $\mathrm{PM}$ within one cycle in the model without considering the shock effect.

The mathematical model under such circumstance is shown as follows.

\subsection{State transition probability within one inspec- tion interval}

Scenario $a$ :

$$
\hat{P}_{a}^{t_{i}}=\frac{\bar{\Phi}_{0}\left(t_{i}\right)}{\bar{\Phi}_{0}\left(t_{i-1}\right)} \frac{\bar{F}\left(t_{i}\right)}{\bar{F}\left(t_{i-1}\right)} .
$$

Scenario $b$

$$
\hat{P}_{b}^{t_{i}}=\int_{t_{i-1}}^{t_{i}} \frac{f(t)}{\bar{F}\left(t_{i-1}\right)} \frac{\bar{\Phi}_{0}(t)}{\bar{\Phi}_{0}\left(t_{i-1}\right)} \frac{\bar{\Phi}_{1}\left(t_{i}\right)}{\bar{\Phi}_{1}(t)} \mathrm{d} t .
$$

Scenario $c$ :

$$
\hat{P}_{c}^{t_{i}}=\int_{t_{i-1}}^{t_{i}} \frac{\bar{F}(t)}{\bar{F}\left(t_{i-1}\right)} \frac{\varphi_{0}(t)}{\bar{\Phi}_{0}\left(t_{i-1}\right)} \mathrm{d} t .
$$

Scenario $d$ :

$$
\hat{P}_{d}^{t_{i}}=\int_{t_{i-1}}^{t_{i}} \hat{\Delta}_{1} \int_{t}^{t_{i}} \hat{\Delta}_{2} \mathrm{~d} t^{\prime} \mathrm{d} t
$$

where

$$
\begin{gathered}
\hat{\Delta}_{1}=\frac{f(t)}{\bar{F}\left(t_{i-1}\right)} \frac{\bar{\Phi}_{0}(t)}{\bar{\Phi}_{0}\left(t_{i-1}\right)}, \\
\hat{\Delta}_{2}=\frac{\varphi_{1}\left(t^{\prime}\right)}{\bar{\Phi}_{1}(t)} .
\end{gathered}
$$

4.2 Mathematical models for the variables in optimization model

The expected time of one cycle is

$$
E(\hat{T})=E\left(\hat{T}_{0}\right)+E\left(\hat{T}_{1}\right)
$$

where

$$
\begin{aligned}
E\left(\hat{T}_{0}\right)= & \int_{0}^{T_{C}} \bar{\Phi}_{0}(t) \bar{F}(t) \mathrm{d} t, \\
E\left(\hat{T}_{1}\right)= & \sum_{i=1}^{N} E\left(\hat{T}_{1 i}\right), \\
E\left(\hat{T}_{1 i}\right)= & \hat{P}\left(S_{0}^{t_{i-1}}\right)\left[\int_{t_{i-1}}^{t_{i}} \hat{P}_{b}^{t_{i}}\left(t_{i}-t\right) \mathrm{d} t\right. \\
& \left.+\int_{t_{i-1}}^{t_{i}} \hat{\Delta}_{1} \int_{t}^{t_{i}} \hat{\Delta}_{2}\left(t^{\prime}-t\right) \mathrm{d} t^{\prime} \mathrm{d} t\right] .
\end{aligned}
$$

4.3 Probability of $\mathrm{PM}, \mathrm{CM}$, and the expected number of inspections in one cycle

The probability of PM and CM, and the expected number of inspections in one cycle are

$$
\begin{gathered}
\hat{P}_{\mathrm{PM}}^{a}=\sum_{i=1}^{N} \hat{P}_{b}^{t_{i}}, \\
\hat{P}_{\mathrm{CM}}=1-\hat{P}_{\mathrm{PM}}, \\
E(\mathrm{IN})=\sum_{i=1}^{m-1} \hat{P}\left(\hat{S}_{0}^{t_{i-1}}\right)\left(\hat{P}_{a}^{t_{i}}+\hat{P}_{b}^{t_{i}}\right), \quad m \geq 2 .
\end{gathered}
$$

\section{Numerical investigation and discussion}

Our numerical example used the data from a specific kind of insulation material for traction motors. A primary assumption is that the times for state transitions all follow a Weibull distribution. The time unit is $10000 \mathrm{~h}$. The shape parameters and scale parameters are $(2.198,96.542)$ for state 0 to state 1 , $(2.653,41.737)$ for state 1 to state 2 , and $(2.207$, 89.246 ) for state 0 to state 2 . The failure rates under extreme shock are 0.0021 and 0.0057 at state 0 and state 1 , respectively.

The basic objective of maintenance optimization is to avoid both excessive and insufficient maintenance and finally reach the best compromise between maintenance cost and reliability. Using the above data, we can obtain the mapping relationship among CPT, $T_{\mathrm{IN}}$, and $N$ as shown in Fig. 3. It can be observed that:

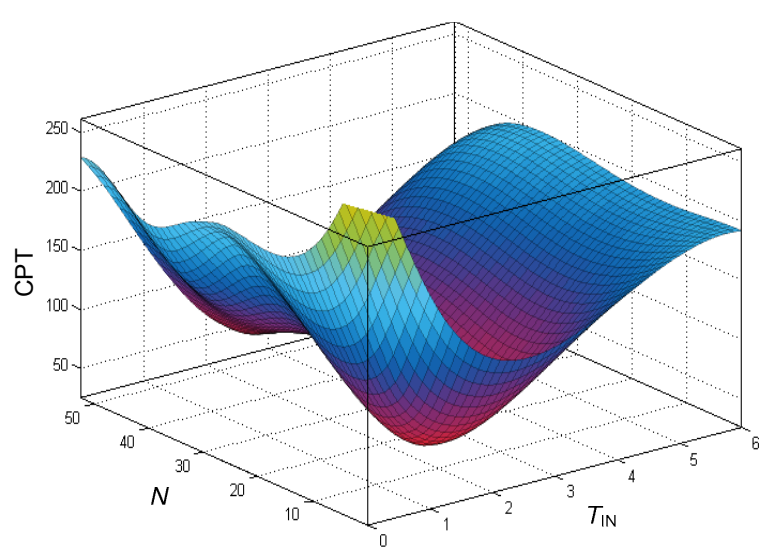

Fig. 3 Mapping relationship among CPT, $T_{\mathrm{IN}}$, and $N$ 
1. The convexity of the surface indicates that there exists an optimal set of $N$ and $T_{\mathrm{IN}}$.

2. The CPT of the proposed model is much higher with a small $N$, which results from the poor availability of traction motor insulations and excessively frequent PM. In this case, excessive maintenance occurs.

3 . For very large $N$, the maintenance strategy turns into a total CBM model. Furthermore, if $T_{\mathrm{IN}}$ is large simultaneously, both the life information and the condition monitoring information are given up. This maintenance transfers to a pure CM strategy and is inevitably costly.

4. At the optimal point, operation cost and failure risk reach the best tradeoff. It can be observed that from this point, with the increase of $T_{\mathrm{IN}}$ and $N$, the risk of sudden functional failure increases greatly because of insufficient maintenance, which will finally lead to expensive CM.

The optimal solutions for $T_{\mathrm{IN}}$ and $N$ are 1.48 and 12 , respectively, and the critical age is 17.76 . In this case, the optimization solution $\hat{T}_{\mathrm{IN}}$ and $\hat{N}$ for the special case are 1.65 and 14, respectively, and the critical age is 23.1 .

The influence of shock parameters on the maintenance strategy is another crucial concern. By varying the values of $\lambda$ and $P_{\mathrm{S} i}$, a group of solutions, listed in Table 1, is obtained. $C \%$ indicates the cost decrease percent between the CPT of the proposed model and that of the optimal solution of the special case. We can observe that:

1. According to the 1 st set of data in Table 1 , for small values of shock frequency as well as small failure rate after shocks, the proposed model is very close to the special case. However, for high frequency of shocks as well as high failure rates after shocks, such as the No. 8 dataset, the pre-defined critical age is too short to fulfill the availability requirements, and it is too expensive to operate under such a situation. It can be concluded that the traction motors are inadequate for working in this case.

2. $T_{\mathrm{IN}}$ is more susceptible to the difference between $P_{\mathrm{S} 0}$ and $P_{\mathrm{S} 1}$. With an increasing difference, more frequent inspections are demanded. In state 1, shocks are more inclined to lead to functional failure and more frequent inspections should be performed to avoid the operation in state 1 .
3. With the increase of the frequency of shocks and failure rate, the optimal critical age decreases. More shocks may lead to the increase of the probability of high-cost CM, and therefore the critical age should be reduced to lower the probability of $\mathrm{CM}$ provoked by time-related internal factors.

4. Comparing with the optimization solution of the special case, both $T_{\mathrm{IN}}$ and $T_{\mathrm{C}}$ are diminished. That means the system will operate under insufficient maintenance if the maintenance strategy obtained from the model of the special case is selected. This may bring about a higher risk of sudden breakdown. With the increase of the shock parameters, the impact of shocks on maintenance strategies becomes more remarkable, and the strategy may even eventually mislead the maintenance actions.

Table 1 Optimization solutions

\begin{tabular}{cccccccc}
\hline No. & $\lambda$ & $P_{\mathrm{S} 0}$ & $P_{\mathrm{S} 1}$ & $N$ & $T_{\mathrm{IN}}$ & $T_{\mathrm{C}}$ & $C \%$ \\
\hline 1 & 0.01 & 0.0004 & 0.0007 & 14 & 1.60 & 22.40 & $0.74 \%$ \\
2 & 0.02 & 0.0017 & 0.0153 & 16 & 1.21 & 19.36 & $3.84 \%$ \\
3 & 0.02 & 0.0021 & 0.0029 & 13 & 1.58 & 20.54 & $4.03 \%$ \\
4 & 0.02 & 0.0150 & 0.0200 & 12 & 1.39 & 16.68 & $5.76 \%$ \\
5 & 0.05 & 0.0021 & 0.0057 & 12 & 1.48 & 17.76 & $5.38 \%$ \\
6 & 0.20 & 0.0004 & 0.0007 & 13 & 1.57 & 20.41 & $1.65 \%$ \\
7 & 0.20 & 0.0170 & 0.0650 & 9 & 1.38 & 12.42 & $13.70 \%$ \\
8 & 1.00 & 0.1000 & 0.1200 & 4 & 1.31 & 5.24 & $40.70 \%$ \\
\hline
\end{tabular}

\section{Conclusions}

We developed an optimization model of PM strategy for traction motor insulations, which combines TBM and CBM as well as taking random shocks into account.

The primary contribution of this study is to work out a feasible and practical CBM strategy for traction motor insulations based on their operating characteristics. Through periodic inspections, an operating mechanism comprising two failure modes and three operating states is proposed, which can make the best use of historic life information and inspection information. Moreover, it can overcome the drawbacks of excessive and insufficient maintenance of traditional time-based maintenance schemes.

Another main contribution is to take extreme shock effect into account in the maintenance model. 
Traction motor insulation is different from normal deteriorating systems because of suffering random extreme shock load during operation. In the proposed model, extreme shocks following a Poisson process are integrated into the maintenance model, which ultimately increases the accuracy of the maintenance model.

Numerical investigation validates that by taking shock effect into account, insulations can operate at a lower risk of catastrophic breakdown, and the operating cost is reduced considerably.

\section{References}

Ahmad, R., Kamaruddin, S., 2012. An overview of timebased and condition-based maintenance in industrial application. Computer \& Industrial Engineering, 63(1): 135-149. [doi:10.1016/j.cie.2012.02.002]

Asadzadeh, S.M., Azadeh, A., 2014. An integrated systemic model for optimization of condition-based maintenance with human error. Reliability Engineering \& System Safety, 124:117-131. [doi:10.1016/j.ress.2013.11.008]

Caballé, N.C., Castro, I.T., Pézrez, C.J., et al., 2015. A condition-based maintenance of a dependent degradationthreshold-shock model in a system with multiple degradation processes. Reliability Engineering \& System Safety, 134:98-109. [doi:10.1016/j.ress.2014.09.024]

Castro, I.T., 2013. An age-based maintenance strategy for a degradation-threshold-shock-model for a system subjected to multiple defects. Asia-Pacific Journal of Operational Research, 30(05):1350016-1350029. [doi:10. 1142/S0217595913500164]

Castro, I.T., Caballé, N.C., Pérez, N.C., 2015. A conditionbased maintenance for a system subject to multiple degradation processes and external shocks. International Journal of Systems Science, 46(9):1692-1704. [doi:10. 1080/00207721.2013.828796]

Chen, J.Y., Li, Z.H., 2008. An extended extreme shock maintenance model for a deteriorating system. Reliability Engineering \& System Safety, 93(8):1123-1129. [doi:10. 1016/j.ress.2007.09.008]

Fang, Y.T., 2011. On China's high-speed railway technology. Journal of Zhejiang University-SCIENCE A (Applied Physics \& Engineering), 12(12):883-884. [doi:10.1631/ jzus.A11GT000]

Gao, Y.C., Feng, Y.X., Tan, J.R., 2014. Multi-principle preventive maintenance: a design-oriented scheduling study for mechanical systems. Journal of Zhejiang UniversitySCIENCE A (Applied Physics \& Engineering), 15(11): 862-872. [doi:10.1631/jzus.A1400102]

Gebraeel, N.Z., Lawley, M.A., Li, R., et al., 2005. Residual life distributions from component degradation signals: a Bayesian approach. IIE Transactions, 37(6):543-557. [doi:10.1080/07408170590929018]
Hu, Q.Y., 1995. The optimal replacement of Markov deteriorative under stochastic shocks. Microelectronics Reliability, 35(1):27-31. [doi:10.1016/0026-2714(94)00074-X]

Lam, Y., 2009. A geometric process $\delta$-shock maintenance model. IEEE Transactions on Reliability, 58(2):389-396. [doi:10.1109/TR.2009.2020261]

Lin, Y.H., Li, Y.F., Zio, E., 2014. Multi-state physics model for the reliability assessment of a component under degradation processes and random shocks. ESREL, Amsterdam, the Netherlands, p.1-7.

Lin, Y.H., Li, Y.F., Zio, E., 2015. Integrating random shocks into multi-state physics models of degradation processes for component reliability assessment. IEEE Transactions on Reliability, 64(1):154-166. [doi:10.1109/TR.2014. 2354874]

Liu, B.Y., Fang, Y.T., Wei, J.X., et al., 2007. Inspectionreplacement policy of system under predictive maintenance. Journal of Zhejiang University-SCIENCE A, 8(3): 495-500. [doi:10.1631/jzus.2007.A0495]

Lu, X.F., Liu, M., 2014. Hazard rate function in dynamic environment. Reliability Engineering \& System Safety, 130:50-60. [doi:10.1016/j.ress.2014.04.020]

Ma, H.Z., 2008. Motor State Monitoring and Fault Diagnosis. China Machine Press, Beijing, China, p.354-370 (in Chinese).

Montoro-Cazorla, D., Pérez-Ocón, R., 2014. A reliability system under different types of shock governed by a Markovian process and maintenance policy K. European Journal of Operational Research, 235(3):636-642. [doi:10.1016/j.ejor.2014.01.021]

Panagiotidou, S., Tagaras, G., 2008. Evalution of maintenance policies for equipment subject to quality shifts and failures. International Journal of Production Research, 46(20):5761-5779. [doi:10.1080/00207540601182260]

Panagiotidou, S., Tagaras, G., 2010. Statistical process control and condition based maintenance: a meaningful relationship through data sharing. Production and Operations Management, 19(2):156-171. [doi:10.1111/j.1937-5956. 2009.01073.x]

Panagiotidou, S., Tagaras, G., 2012. Optimal integrated process control and maintenance under general deterioration. Reliability Engineering \& System Safety, 104:58-70. [doi:10.1016/j.ress.2012.03.019]

Shi, H., Zeng, J.C., 2014. Preventive maintenance strategy based on life prediction. Computer Integrated Manufacturing Systems, 20(5):1133-1140 (in Chinese).

Tang, D.Y., Makis, V., Jafari, L., et al., 2015. Optimal maintenance policy and residual life estimation for a slowly degrading system subject to condition monitoring. Reliability Engineering \& System Safety, 134:198-207. [doi:10.1016/j.ress.2014.10.015]

Tang, Y.Y., Lam, Y., 2006. A $\delta$-shock maintenance model for deteriorating system. European Journal of Operational Research, 168(2):541-556. [doi:10.1016/j.ejor.2004.05. 006] 
van Noortwijk, J.M., 2009. Survey of the application of gamma processes in maintenance. Reliability Engineering \& System Safety, 94(1):2-21. [doi:10.1016/j.ress. 2007.03.019]

Wang, Z., Huang, H.Z., Li, Y., et al., 2011. An approach to reliability assessment under degradation and shock process. IEEE Transaction of Reliability, 60(4):852-863. [doi:10.1109/TR.2011.2170254]

Yang, Y., Klutke, G.A., 2000. Lifetime-characteristics and inspection schemes for levy processes. IEEE Transactions on Reliability, 49(4):377-382. [doi:10.1109/24. 922490]

Yao, Y.Z., Meng, C., Wang, C., et al., 2013. Optimal preventive maintenance policies for equipment under condition monitoring. Computer Integrated Manufacturing Systems, 19(12):2968-2975 (in Chinese).

Yin, H., Zhang, G.J., Zhu, H.P., et al., 2015. An integrated model of statistical process control and maintenance based on the delayed monitoring. Reliability Engineering \& System Safety, 133:323-333. [doi:10.1016/j.ress.2014. 09.020]

Zhou, K., Wu, G.N., Deng, T., et al., 2006. Aging time effect on $\mathrm{PD}$ and space charge behavior in magnet wire under high PWM voltage. IEEE International Symposium on Electrical Insulation, Toronto, Canada, p.159-162. [doi:10.1109/ELINSL.2006.1665281]

\section{中文概要}

题 目: 基于周期性监测的牵引电机绝缘最优视情维修 决策

目 的：充分利用寿命信息, 并考虑冲击效应对维修策 略的影响, 提出符合牵引电机绝缘运行特征的 最优视情维修策略。

方 法: 1. 采用正常状态、潜在故障状态与功能故障状 态描述牵引电机绝缘运行状况; 2. 应用泊松过 程描述随机高电压冲击; 3. 以单位时间的运行 成本为目标函数, 以监测间隔和预防性维修寿 命阈值为优化变量, 建立最优视情维修决策 模型。

结 论：该模型能显著降低牵引电机绝缘功能故障的风 险, 同时降低单位时间运行成本。

关键词: 牵引电机绝缘; 视情维修; 预防性维修; 冲击 